\title{
Los vota de obispos latinoamericanos sobre vida religiosa (I) ¿Retrato de una forma de vida o de una eclesiología preconciliar?
}

\author{
Virginia R, AzcuY \\ Pontificia Universidad Católica de Chile \\ Carla E. Ferreyra \\ Pontificia Universidad Católica Argentina \\ reqazvi@gmail.com \\ Recibido 20.04.2021/ Aprobado 15.05.2021 \\ DOI: https://doi.org/10.46553/teo.58.135.2021.p113-140
}

\section{RESUMEN}

En el marco de un proyecto de investigación continental sobre el Concilio Vaticano II y su recepción en América Latina y el Caribe, que es parte de una iniciativa internacional más amplia, el presente estudio ofrece una visión general de los vota de los obispos sobre la vida religiosa en Argentina, Brasil, Colombia y México, en respuesta a la consulta encargada por Juan XXIII. El relevamiento se ubica en el contexto histórico eclesial, se concentra en una descripción de los vota según las Acta ef Documenta conciliares (serie antepreparatoria) y se orienta hacia una lectura interpretativa sobre la vida religiosa en el contexto de la eclesiología preconciliar.

Palabras clave: "Vota" de obispos latinoamericanos; Concilio Vaticano II; Vida religiosa; Eclesiología pre-conciliar; Fase ante-preparatoria; Iglesia en América Latina y el Caribe.

The "Vota" of Latin American Bishops about Religious Life (I).

Portrait of a Way of Life or a Preconciliar Ecclesiology?

- La Dra. Azcuy es profesora investigadora de la Pontificia Universidad Católica de Chile, Facultad de Teología. La profesora Carla Ferreyra es Asistente de investigación de la Pontificia Universidad Católica Argentina, Facultad de Teología. 


\section{ABSTRACT}

In the context of a continental research project about the Second Vatican Council and its reception in Latin America and the Caribbean, which is, in turn, part of a larger international initiative, this paper (part one) provides a general view of the vota of the bishops about religious life in Argentina, Brazil, Colombia, and Mexico in response to the query sent out by John XXIII. This study is framed within the historical ecclesiastic context, its focus is on the description of the vota according to the Acta et Documenta of the Council (antepreparatory series), and it is oriented towards an interpretive reading of religious life with emphasis on the context of preconciliar ecclesiology.

Key Words: "Vota" of the Bishops about Religious Life; Second Vatican Council; Religious Life; Preconciliar Ecclesiology; Antepreparatory Period; Church in Latin America and the Caribbean.

Los estudios especializados sobre el Concilio Vaticano II en las últimas décadas han mostrado una y otra vez la importancia de la investigación histórica de las fuentes para una adecuada interpretación teológica del acontecimiento y sus textos. ${ }^{1}$ La profunda renovación que estos suscitaron no puede ponderarse correctamente si no se tienen a la vista la evolución de los diversos asuntos en las décadas precedentes, los impulsos de cambio y las discusiones principales de los años previos a este concilio. Los vota que los diversos obispos de todo el mundo enviaron a Roma, en respuesta a la consulta encargada por Juan XXIII, en la fase antepreparatoria del Concilio, pueden ser un buen observatorio para analizar en qué punto se encontraban entonces las iglesias locales y cuáles eran las preocupaciones de la jerarquía católica. ${ }^{2}$ En palabras de Antonio Melloni, los vota pueden ofrecer "un retrato de la Iglesia" o "un retrato del mosaico de la Iglesia", aunque más no sea de forma condicionada e incompleta. ${ }^{3}$ En este contexto se ubica la pregunta fundamental que encuadra estas reflexiones: ¿se trata, en estos votos, de una visión

1 Cf. Carlos Schickendantz, «Las investigaciones históricas sobre el Vaticano II. Estado de la cuestión y perspectivas de trabajo», Teología y Vida 55 (2014): 105-141.

2 Cf. Étienne Fouilloux, «La fase antepreparatoria (1959-1960). El lento camino para salir de la inercia», en: Giuseppe Alberigo (dir.), Historia del Concilio Vaticano II, Volumen I, El catolicismo hacia una nueva era, el anuncio y la preparación (enero 1959-septiembre 1962) (Salamanca: Ediciones Sígueme, 1999), 63-154.

$3 \mathrm{Cf}$. Antonio Melloni, «Per un approccio storico-critico ai Consilia et vota della Fase Antepraeparatoria del Vaticano Il»s, Rivista di storia e letteratura 26,3 (1990): 556-576, 556. 
sobre la vida religiosa o de un retrato de la eclesiología pre-conciliar latinoamericana y centroamericana? Las temáticas vinculadas a religiosas y religiosos, muy presente en las propuestas de los obispos del continente, explican la centralidad de esta cuestión y ponen de manifiesto diversos interrogantes.

Los votos sobre vida religiosa de los obispos de América Latina y América Central -conforme a la división geopolítica de la época- formaron parte de más de un cuarto del total de vota llegados a Roma en relación con el tema. Si bien existen algunos estudios sobre estos votos latinoamericanos ${ }^{4}$-o de algunos países en particular- ${ }^{5}$ no se conocen publicaciones que traten específicamente sobre los vota de la región acerca de la vida religiosa en la fase antepreparatoria. La obra alemana de Joachim Schmiedl sobre el Concilio y esta forma de vida, Das Konzil und die Orden, sirve sin duda de referencia, aunque no contiene un estudio pormenorizado sobre los votos latinoamericanos; ${ }^{6}$ así también otros estudios sobre ellos o por países que incluyen información sobre la vida religiosa durante la preparación y la celebración del Vaticano II. ' En cuanto a las fuentes de la investigación, se utilizan las Acta et Documenta Concilio Oecumenico Vaticano II Apparando (serie antepreparatoria) en vistas a localizar, entre los vota de obispos latino- y centroamericanos, aquellos que se refieren a la vida religiosa en los diversos países que respondieron a la consulta del Cardenal Tardini (1959), para luego seleccionar y ponderar los más significativos. ${ }^{8}$

4 Cf. José Oscar Beozzo (ed.), Cristianismo e iglesias de América Latina en visperas del Vaticano II (San José: Editorial Dei, 1992); Rodrigo Polanco, "La Iglesia continental que Ilegaba al Concilio. Eclesiología de los vota de los obispos latinoamericanos para el Concilio Vaticano Il», Perspectiva Teológica 52 (2020): 705-731.

5 Cf. Ernesto Salvia, «La recepción del Concilio Vaticano II en la Argentina», Archivum 30 (2014): 299-310.

6 Joachim Schmiedl, Das Konzil und die Orden. Krise und Erneuserung des gottgeweihten Lebens (Vallendar-Schönstatt: Patris Verlag, 1999), 160-225. La obra representa un estudio sistemático sobre vida religiosa en el Vaticano II.

7 A modo de ejemplo, puede citarse a Luis Liberti SVD, Los obispos argentinos en el Concilio Vaticano I/ (Buenos Aires: Ágape Libros/Editorial Guadalupe, 2015), 62-68.

8 Estos votos se encuentran publicados en Acta et Documenta Concilio Oecumenico Vaticano II Apparando: Consilia et vota episcoporum et praelatorum. Series I: Antepraeparatoria (Vaticanus: Typis Poliglottis Vaticanis, 1960-1961), Vol. II, Pars VI-VII [en adelante, se cita con la sigla ADAP]. 
El proyecto continental en curso con el título "El Vaticano II como orientación para la Iglesia y las teologías del siglo XXI. Recepción y prospectivas en Latinoamérica y el Caribe" (2018-2020), bajo la coordinación del Pbro. Dr. Carlos Schickendantz (Universidad Alberto Hurtado, Chile), sirve de marco a la investigación cuyos primeros resultados se dan a conocer en este estudio. El mencionado proyecto hace parte de otro proyecto internacional, intercultural e intercontinental, con el tema "The Second Vatican Council in Intercontinental and Intercultural Perspectives - Orientation and Motivation for the Theologies of the 21st Century" (2018-2025), en desarrollo con grupos de trabajo en los cinco continentes y coordinado por el Prof. Dr. Joachim Schmiedl (Philosophisch-Theologische Hochschule de Vallendar, Alemania) ${ }^{9}$

El presente estudio, publicado en dos partes en la revista Teología, ofrece una visión general sobre los vota de los obispos latinoamericanos relativos a la vida religiosa en el conjunto de los países con mayor número de respuestas a la consulta: Argentina (33), Brasil (116), Colombia (35) y México (37). La reflexión se inicia con una contextualización histórico-eclesial sobre esta forma de vida en Latinoamérica antes del Concilio, con el fin de ubicarla en las coordenadas de tiempo y espacio, a la vez que su relación con el magisterio universal. En este horizonte, se presenta una descripción de los votos por países, que incluye algunos aspectos materiales y un mapa de contenidos, con detalle de los asuntos más relevantes y más típicos por país. El momento interpretativo aborda la cuestión relativa al significado de estas propuestas, buscando un equilibrio entre la sobrevaloración y la indiferencia e intentando superar la mera descripción, según el desafío planteado por A. Melloni. ${ }^{10}$ Para concluir, se realiza una primera ponderación de resultados del relevamiento, en la cual se trata de observar la visión teológica emer-

9 Para más información sobre el proyecto, véase: https://www.pthv.de/forschung/projekte-theologie/uebersicht-projekte-theologie/projekte-in-der-historischen-theologie/vatican-ii-legacy-and-mandate/

$10 \mathrm{Cf}$. Melloni, «Per un approccio storico-critico ai Consilia et vota della Fase Antepraeparatoria del Vaticano II», 560 y 576. 
gente en las peticiones sobre la vida religiosa y su relación con la eclesiología preconciliar subyacente, con sus elementos de renovación en germen.

\section{Contextualización histórico-eclesial de la vida religiosa antes del Vaticano II}

Se habla de "visión histórica" o "memoria histórica" de la vida religiosa en América Latina y el Caribe, porque una historia global no ha sido todavía escrita, ${ }^{11}$ aunque sí historias de la Iglesia, latinoamericanas o nacionales, estudios de órdenes, congregaciones religiosas, santos/as y beatos/as. Las congregaciones religiosas antiguas fueron renovadas en el siglo XX por personal extranjero, lo cual resultó fundamental para la supervivencia y la adecuación, aunque eso también influyó en el modelo que se asimiló y que dejó sus huellas. ${ }^{12}$ El crecimiento de las religiosas en la primera mitad del siglo fue exponencial y superó en número, por más del doble, a clérigos y religiosos juntos: de 14.000 religiosas en 1912 pasaron a 55.567 en 1945 y 69.073 en 1950; los clérigos eran 11.776 y aumentaron a 12.992 y 14.270 y los religiosos eran 4.578 y llegaron a ser 11.389 y 13.282 respectivamente. ${ }^{13} \mathrm{El}$ incremento se relaciona con el llamamiento de misioneros/as para América Latina y tal vez también el suceso de la Segunda Guerra Mundial; los países con mayor presencia de vida religiosa son Brasil, México, Colombia y Argentina. Los orígenes sociales y étnicos de quienes ingresaban a la vida consagrada en América Latina y el Caribe eran variados; en general provenían de sectores medios, más rurales que urbanos y étnicamente su origen era mestizo en países como Guatemala, Colombia

11 Cf. Noë Zeballos, «Visión histórica de la vida religiosa en América Latina», en Víctor Codina; Noë Zeballos, Vida Religiosa. Historia y Teología (Madrid: Ediciones Paulinas, 1987), 75-108, 76; Confederación Latinoamericana de Religiosos (CLAR), Vida religiosa femenina en América Latina y el Caribe. Memoria histórica 1959-1999 (Lima: CEP, 2003), 3 volúmenes.

12 Cf. Maria Carmelita De Freitas, «La vida religiosa en América Latina en los últimos cuarenta años. Una relectura a partir de la experiencia», en Pablo Richard (dir.), 10 palabras clave sobre la Iglesia en América Latina (Estella: Verbo Divino, 2003), 231-264.

13 Ana María Bidegain, «Mujeres, empoderamiento e instituciones religiosas en la historia latinoamericana», Stromata LXIV (2008): 139-1 50, 143. 
y México o blanco y de clases medias como en Chile, Argentina o Uruguay. Las comunidades no eran ajenas a las diferencias y prejuicios sociales existentes, que reproducen en su interior, como se documenta para el caso de Brasil. ${ }^{14}$ Todavía hasta los años ' 60 y ' 70 , en algunas comunidades, se daba la presencia de dos clases sociales: las hermanas del coro, provenientes de clase alta o media alta y las hermanas coadjutoras, de clase media, popular y rural, con diferentes cargos y tareas. Las misiones entre los indígenas florecieron en diversos países como México, Guatemala, Panamá, Colombia, Venezuela, Ecuador, Perú, Bolivia, Brasil.

A principios del siglo $X X$, la comprensión de la vida religiosa estaba marcada por la doctrina tomista del "estado de perfección", si bien en las décadas de los años cuarenta y cincuenta se empezaban a dar algunos indicios de una renovación, en parte promovida por Pío XII. ${ }^{15}$ Como sucedía en otros contextos antes del Concilio, en América Latina esta forma de vida cristiana se comprendía como estado de perfección, se vivía con un cierto sentido de aristocracia espiritual respecto a los laicos; las religiosas y los religiosos participaban de la visión de una Iglesia clerical, juridicista y triunfalista, típica de la eclesiología preconciliar. ${ }^{16}$ En concreto, la vida religiosa estaba centrada en la observancia regular: normas, Constituciones, reglas, horarios y costumbres eran la manifestación de la voluntad de Dios y el medio para la perfección. Por eso, se daba mucha importancia a la obediencia, la reglamentación de la vida comunitaria y el cumplimiento.

14 Cf. José Oscar Beozzo, «Vida cristiana y sociedad en Brasil», en José Oscar Beozzo (ed.), Cristianismo e iglesias de América Latina en visperas del Vaticano II (San José: Editorial Dei, 1992), 49-81; José Oscar Beozzo; Ir. M. Raimunda R. Costa; Ir. M. Fidêncio E. Santo; Ir. Geralda F. Silva, Tecendo memórias, gestando futuro. História das Irmãs Negras e Indigenas Missionárias de Jesus Crucificado - MJC (São Paulo: Paulinas, 2009).

15 Cf. Friedrich Wulf, «Fenomenología teológica de la vida religiosa», en: Johannes Feiner; Magnus Löhrer (dir.), Mysterium Salutis. Manual de Teología como historia de salvación, Vol. IV, II (Madrid: Cristiandad, 1975), 438-472.

16 Cf. Víctor Codina, «Vida Religiosa, pasión por el Evangelio y por el pueblo. Hermenéutica de los documentos del Vaticano II sobre Vida Religiosa», en Memorias Congreso de VC (Bogotá: Confederación Latinoamericana de Religiosos-CLAR, 2015), 79-97, 79-80. 
El esfuerzo de renovación impulsado por Pío XII fue indudable, pero no tuvo frutos inmediatos: se hablaba de renovar, pero no había cambios sustantivos. ${ }^{17}$ Por entonces, el aggiornamento de la vida religiosa, su adaptación a las exigencias del tiempo presente y su modernización se impulsa "desde arriba". Pío XII tenía un interés particular al respecto, por el vínculo estrecho de religiosos a la curia y por la importancia fundamental de sus puestos. Entre las iniciativas del pontífice, se cuentan -entre otras- algunas dignas de mención particular: apertura a los institutos seculares, que introducían una relación positiva con el mundo y la novedad de una vida de perfección fuera de los muros; los impulsos de renovación de la vida contemplativa; el florecimiento de nuevos carismas espirituales; la renovación y organización de la vida religiosa; su colaboración con el clero.

Hacia mediados del siglo $X X$, comenzaron a manifestarse en América Latina algunos impulsos de renovación, entre los cuales tanto historiadores/as como teólogos/as y otros/as protagonistas de la vida eclesial suelen destacar dos formas de vida consagrada que aportaron especialmente al cambio: la primera fueron las fundaciones inspiradas por Carlos de Foucauld (1848-1916), con una vida evangélica y una presencia caritativa en medios pobres que puede señalarse como uno de los antecedentes de la inserción. La segunda forma novedosa fue la de los institutos seculares (19471948), como llamada a vivir los consejos evangélicos en el mundo: sin hábito, ni casas comunes, ni instituciones propias, con su profesión, oficio o trabajo. Una mayor cualidad inspiradora suele atribuirse a la primera de estas formas de vida, aunque ambas ilustran el giro hacia lo secular.

La fraternidad o Instituto de los pequeños Hermanos de Jesús, fundada por René Voillaume en 1946, llegó a Chile en 1951 por una petición que le hizo San Alberto Hurtado cuando conoció las comunidades obreras en Francia en 1947 y marcó el rumbo hacia la 
Iglesia de los pobres. ${ }^{18}$ Ya en 1945 los Hermanitos habían comenzado a vivir en pequeñas comunidades en ambientes populares, pasando del mundo del desierto al ámbito secular del trabajo; la síntesis espiritual que se hacía presente en Latinoamérica constaba de tres elementos: pobreza, trabajo manual y contemplación. En el caso de las Hermanitas de Jesús, fundadas por Magdeleine Hutin en 1939 y con llamada a los pobres desde 1946, la llegada a América Latina sucedió en 1952. La contribución que trajeron estas comunidades puede resumirse con la palabra "inserción" -si bien el término no era utilizado en esos años, sino que fue incorporado con posterioridad-, que alude a una localización -geográfica, social y teologal- en medio del mundo de los pobres y excluidos según la encarnación. ${ }^{19}$ Como lo expresó R. Voillaume en uno de sus libros más leídos en nuestro ámbito, antes y después del Concilio, se trataba de vivir en el corazón de las masas, mediante un apostolado de presencia que daba testimonio de la realidad de Dios. ${ }^{20}$ Aun con pocos seguidores, la vida de estas comunidades interpeló a la vida consagrada contemporánea e influyó fuertemente en la espiritualidad y la pastoral de América Latina, junto a los sacerdotes obreros de Francia y a otras iniciativas misioneras y de irradiación espiritual que marcaron rumbo en los años que prepararon el Concilio.

Los aires de renovación se fueron plasmando lentamente y en esta evolución fue una importante el que se fueran dando algunos pasos en la organización de la vida religiosa, lo que preparó los cambios que se irían dando con el transcurso del tiempo. A esto contribuyeron diversos factores, entre los que cabe destacar al

18 Cf. Alberto Hurtado; Jaime Castellón (ed.), Cartas de San Alberto Hurtado S.J. (Santiago: Ediciones Universidad Alberto Hurtado, 2017), 358; Mons. Manuel Larraín; Mons. Bernardino Piñera; P. Juan Ochagavía; Antonio Bentué, Arar en la esperanza. El Concilio Ecuménico Vaticano II: faro y tarea pendiente (Chile: Verbo Divino, 2014), 152.

19 Cf. Virginia Raquel Azcuy, «La inserción como fruto del aggiornamento conciliar», en Ana Lourdes Suárez; Brenda Carranza; Mariana Facciola; Lorena Fernández Fastuca (eds.), Religiosas en América latina: memorias y contextos (Buenos Aires: Instituto de Investigaciones Facultad de Ciencias Sociales UCA - CONICET, 2020), 329-335.

20 La edición original en francés de René Voillaume, Au coeur de masses es de 1950 y alcanza los 50 mil ejemplares en 1955 y 100 mil en 1969, con traducciones a más de quince lenguas. 
menos tres: ${ }^{21}$ los Congresos sobre los Estados de Perfección impulsados por Pío XII entre 1950 y 1957; la I Conferencia General del Episcopado de América Latina en 1955 y la creación de la CLAR, Confederación Latinoamericana de Religiosos en 1959. El primer congreso se realizó en Roma en 1950, para la renovación de la teología, la vida y el apostolado, así como la organización de las órdenes y congregaciones. Argentina fue sede de un Congreso Internacional de los Estados de Perfección (Buenos Aires 1954), en el cual participaron 5.000 religiosas y 1.000 religiosos del país, Bolivia, Chile, Paraguay y Uruguay, pero -según los testimonios- no hubo espíritu renovador. ${ }^{22}$

Entre los temas programados para la Conferencia de Río de Janeiro, celebrada en 1955, el primero era «la escasez de sacerdotes, a la cual se debía responder por la intensificación del trabajo en favor de las vocaciones sacerdotales y por la ampliación del apostolado de los laicos de la Acción Católica». ${ }^{23}$ En cuanto a la vida religiosa, la Carta Apostólica Ad Ecclesiam Christi de Pío XII destacó la cooperación fraternal de los religiosos con el clero secular. A ella se le solicitó «ayudar a los Párrocos de las Diócesis, seculares o religiosas, en sus múltiples ministerios parroquiales, de modo especial en los suburbios de las grandes ciudades y en las zonas alejadas de las parroquias más extensas» ( $\mathrm{N}^{\mathrm{0}} 35$ ). Algunos obispos propusieron que las mujeres religiosas se encargaran de diversas actividades en las parroquias: ${ }^{24}$ catequesis en los barrios, ejercicios espirituales, apertura de obras sociales parroquiales. En algunos países, se propuso que las religiosas se hicieran cargo de parroquias: Mons. Eugenio Sales en Brasil (1953); algo semejante se dio en Chile (1963) y en Uruguay. Entre las parroquias animadas por comunidades religio-

21 Cf. Bidegain, Participación y protagonismo de las mujeres en la historia del catolicismo latinoamericano, 139-152.

22 Cf. Ana Quiñones, STJ, Del "estado de perfección" a "seguir a Jesús con el pueblo pobre". El comienzo de la vida religiosa inserta en medios populares en Argentina (1954-1976) (Buenos Aires: Talleres Gráficos de IRO, 1999), 17ss.

23 Beozzo, «Vida cristiana y sociedad en Brasil», 51.

24 Cf. Bidegain, Participación y protagonismo de las mujeres en la historia del catolicismo latinoamericano, 140ss. 
sas femeninas en Uruguay, se registran antecedentes en cinco de las diez diócesis del país: Melo, Canelones, Mercedes, Florida y la Arquidiócesis de Montevideo, se destaca la presencia de las Hermanas Misioneras Franciscanas del Verbo Encarnado desde 1949, en la parroquia Sagrado Corazón de Jesús (La Florida). Monseñor Carlos Parteli, arzobispo de Montevideo desde 1966, reconoció que el ingreso de religiosas a parroquia no sólo fue útil ante la falta de sacerdotes, sino para abrir un camino pastoral nuevo. ${ }^{25}$

Entre las nuevas estructuras que fueron favorables para la vida religiosa en América Latina, se recuerda y comenta la creación de la Confederación de Religiosos en 1959, que presenta un valor fundamental. La creación de la CLAR, a petición del CELAM, fue un hecho de gran trascendencia, aunque su verdadero impulso en la renovación lo alcanzó después del Concilio, sobre todo hacia fines de los sesenta y principios de los setenta. ${ }^{26}$ La contribución de la CLAR en la renovación y la formación de esta forma de vida en América Latina y el Caribe, sobre todo a partir de Medellín, resulta indiscutible. V. Codina comenta que «luego de los primeros momentos de incertidumbre, a partir de 1966 emprende un cambio seguro de iluminación, apoyo y ayuda a las congregaciones de América Latina». ${ }^{27}$ Transcurridos los primeros años de la institución y con el impulso conciliar, la CLAR crea un grupo de teólogos que reflexionan sobre los diversos temas de vida religiosa. La metodología de este grupo fue quizás lo más interesante, puesto que reflexionó en constante diálogo con las bases, mediante envío a comunidades, recepción de aportes y posterior reelaboración, lo que dio lugar a una serie de publicaciones orientadas a la tarea de recepción y adaptación.

25 Cf. Nelda Rivas, Ellas fueron a anunciarlo. Parroquias animadas por comunidades religiosas femeninas en Uruguay (Montevideo: OBSUR/Doble clic editoras, 2008), 165.

26 Cf. Carlos Palmés, La vida religiosa en América Latina (Cochabamba: Verbo Divino, 72005), 33. Cursiva agregada.

27 Codina, «Visión histórica de la vida religiosa en América Latina», 102. 


\section{Descripción de vota sobre vida religiosa por países}

El porcentaje de respuestas a la consulta del Cardenal Tardini en América Latina fue el más alto, llegando a sumar un $88,1 \%$. En cuanto a su caracterización general, según J. Schmiedl, los obispos de esta región se ubicaron en general como parte del grupo intransigente, de acento jurídico por la participación de canonistas; no tuvieron representación en el grupo caracterizado por el tono pastoral y de reflexión teológica, de cuño europeo; sí estuvieron representados en el grupo destacado por su preocupación por el tema político y social, como se expresó de manera típica en el caso de Brasil. ${ }^{28}$ En los vota sobre vida religiosa de América Latina y América Central, como sucedió en la Iglesia mundial, el tema de la exención fue dominante y marcó la preocupación de los obispos, en relación con el clero y la actividad apostólica en las diócesis. ${ }^{29}$ La insistencia en el tema de la exención evidencia el interés de los obispos por limitar los privilegios de religiosas y religiosos en vistas a una mayor dependencia de su potestad jurisdiccional y pastoral. Los votos en respuesta a la consulta romana también consideraron otros temas tales como la relación obispos y religiosas/os, la unidad y la colaboración entre el clero secular y el regular, los religiosos a cargo de parroquias, la institución de diáconos -sobre todo laicos, aunque también religiosos-, temas relativos a vida religiosa femenina, diversos aspectos económicos, aspectos relativos a la adaptación -hábitos o vestimentas-, los institutos seculares, entre otros. El objetivo de esta sección es presentar una descripción de los vota en los países con más respuestas a la consulta, que son a su vez los que tienen una mayor presencia de comunidades y personas consagradas: Argentina, Brasil, Colombia

28 Cf. Schmied, Das Konzil und die Orden, 160 ss.

29 En el derecho canónico, la palabra exención ha significado en sentido general liberar a uno de una obligación y de sus efectos o de la sumisión a un superior. En el CDC-17, comúnmente se ha identificado con el privilegio de la exención del cual gozaban los regulares y algunas congregaciones de votos simples y definida como la sustracción de la sumisión al ordinario del lugar. Cf. Julio García Martín CMF, Voz «Exención», en A. Aparicio Rodríguez CMF; Joan M. Canals Casas CMF (dir.), Diccionario Teológico de la Vida Consagrada (Madrid: Publicaciones Claretianas, 2009), 640-648.

$30 \mathrm{Cf}$. Schmiedl, Das Konzil und die Orden, 187. 
y México. ${ }^{31}$ En esta exposición, se privilegia una breve contextualización de cada país y una descripción de los votos sobre todo en relación con sus contenidos -temas, frecuencia y significatividad-.

\subsection{Argentina}

En el contexto de la Iglesia en Latinoamérica, el nuevo estatuto de las Conferencias Episcopales apuntaba a fortalecer y dar mayor cohesión a los episcopados internamente, tanto en sus relaciones con los gobiernos de turno como en los esfuerzos pastorales conjuntos. En el caso de la Argentina, ${ }^{32}$ la cohesión y el fortalecimiento costaron más trabajo a causa de divisiones internas que tenían origen en las opciones políticas y visiones sociológicas de los miembros del episcopado. La noticia de la convocatoria de un nuevo concilio ecuménico fue recibida, en gran parte, en el ámbito de búsquedas de respuestas a los desafíos pastorales de la época: en la fase que se extendió entre la consulta y el inicio del Vaticano II, varios obispos escribieron cartas pastorales que aludían al concilio a celebrarse en Roma y difundieron sus objetivos; promovieron cursos y reflexión sobre diversos temas que, en parte, coincidieron con las propuestas enviadas. En los estudios teológicos de la época, se evidenciaba «la necesidad de la reforma de la vida religiosa de ambos sexos; su formación y su cooperación con la vida apostólica de las diferentes diócesis». ${ }^{33}$

En cuanto a la comprensión de los vota, desde una mirada sociológica, F. Mallimaci realiza una observación que también podría servir para los demás países de Latinoamérica: «los obispos y el clero se autocomprenden -en esta época- como el "núcleo" de la

31 En segunda línea se encuentran: Chile, Ecuador, Perú y Venezuela, con 20, 17, 27 y 17 votos totales, respectivamente. Cf. Polanco, «La Iglesia continental que llegaba al Concilio», 706-712.

32 Cf. Salvia, «La recepción del Concilio Vaticano II en la Argentina», 301.309.

33 Salvia, «La recepción del Concilio Vaticano II en la Argentina», 303. 
Iglesia». ${ }^{34} \mathrm{Al}$ momento de la consulta existían en Argentina 2.120 sacerdotes diocesanos y 2.661 sacerdotes religiosos. Los obispos argentinos que participaron con su respuesta a la consulta de la Comisión fueron 33, de los cuales algunos se sumaron a la iniciativa con entusiasmo y otros mantuvieron un rol más bien pasivo. En sus votos se evidencia que la mayoría de los obispos estaban preocupados por su relación con el clero y la parroquia; algunos proponían medidas de mayor subordinación y otros, iniciativas de trabajo colectivo y participativo; faltan las referencias al contexto histórico. ${ }^{35}$ Entre estas respuestas de obispos argentinos se encuentran quince vota sobre diversas cuestiones relativas a la vida religiosa. ${ }^{36}$ En ocho de estos votos se menciona explícitamente la exención y otros la tratan desde la necesidad de fortalecer la autoridad de los obispos, sobre todo en lo que refiere a la participación de los religiosos en las tareas pastorales, en la cooperación con el clero secular, en la asistencia a las zonas más pobres para una correcta distribución del clero y en la posibilidad de mejorar la comunicación. El voto de Enrique Rau puede ejemplificar algunos de los temas más frecuentes: «Es conveniente que se restrinja la exención de los religiosos al menos en algunos casos. Más bien es urgente su subordinación al obispo. Asimismo, pienso que se debe restringir la facultad de los religiosos relativa a las parroquias "de pleno derecho". Es necesario distinguir bien la extensión de facultades de los párrocos y de los superiores, y urge una mayor cooperación sincera entre ambos cleros en las cosas que atañen al apostolado» (ADAP I-II, VII, 62). Otro voto de interés, que cita las palabras de Pío XII en el Congreso de Estados de Perfección (Roma 1950) es el de Jorge Kemerer, al recordar que: «Sin nin-

34 Fortunato Mallimaci, «Argentina», en José Oscar Beozzo, (ed.), Cristianismo e iglesias de América Latina en vísperas del Vaticano I/ (San José: Editorial Dei, 1992), 97-120, 101.

$35 \mathrm{Cf}$. Mallimaci, «Argentina», 110.

36 En orden cronológico, según la fecha de respuesta y la puntualidad solicitada, son los siguientes: Kemerer (Posadas), Marozzi (Resistencia), Aguirre (San Isidro), Plaza y Primatesta (arzobispo y auxiliar de La Plata, respectivamente), Tortolo (auxiliar de Paraná), Castellano (arzobispo de Córdoba), Aramburu (arzobispo de Tucumán). Las respuestas enviadas con demora son las de Schell (Lomas de Zamora), Fasolino (arzobispo de Santa Fe), Rau (Mar del Plata), Raspanti (Morón), Esorto (arzobispo de Bahía Blanca). Y los vota que constan sin fecha son los de Iriarte (Reconquista) y Marengo (Azul); también envió su propuesta en plazo el nuncio apostólico Mozzoni (Buenos Aires). 
guna duda, por el segundo precepto de derecho divino, el sacerdote secular o religioso debe ejercer su ministerio como colaborador del obispo y bajo su dirección. Verdaderamente la misma exención del orden de los religiosos de ningún modo se opone al principio constitucional dado por Dios a la Iglesia; y la misma exención nunca se contradice a la ley por causa de la cual el sacerdote debe obediencia al obispo» (ADAP I-II, VII, 69). Siendo religioso del Verbo Divino, Kemerer da muestras de la importancia del magisterio pontificio en cuanto a la obediencia que se debe al obispo por el sacerdocio.

En otros votos se presentan diversos temas: la exención y la regulación de las parroquias "de pleno derecho" entregadas a los religiosos, así como las dificultades que se plantean con los religiosos que no quieren ir a zonas pobres (N. Fasolino). En lo que refiere a la adaptación de los institutos a los tiempos presentes, también se mencionan la formación de las religiosas (J. C. Aramburu), la posibilidad de que las religiosas se dediquen a la enseñanza de la religión (M. Raspanti) y la simplificación del hábito (J. Iriarte). En cuanto a la organización de institutos aparecen la supresión o modificación de institutos que estén impedidos de realizar su objeto y su fin propios, así como la solicitud de no erigir nuevas casas si no hay suficientes miembros (J. Iriarte).

\subsection{Brasil}

A nivel de organización, en 1952 se creó la CNBB como asamblea de cardenales y arzobispos y en 1958 se convirtió, por estatutos, en una organización de todos los obispos de Brasil. En 1954, cinco años antes de la creación de la CLAR, se creó la Conferencia de Religiosos en Brasil y en 1955 su revista. Ambas instituciones trabajaron en colaboración, dando lugar a una nueva conciencia ético-social del evangelio en Brasil. En la década del cincuenta se dio una gran vitalidad en la reflexión teológica y bíblica, que coexistió con un punto crítico principal que fue la escasez de clero y, en el ad extra, con las diversas amenazas ideológicas como el espiritismo, el 
protestantismo, la masonería y el comunismo. Según O. Beozzo, el tema dominante del período fueron las vocaciones sacerdotales y religiosas, con una fuerte europeización del personal consagrado desde finales del siglo XIX, que comenzó a replantearse a nivel institucional a partir de 1958 con la decisión de iniciar un «reclutamiento de religiosos entre el elemento de color». ${ }^{37}$ Un dato de interés, para comprender las perspectivas de cooperación, unidad y dependencia en las relaciones entre el clero secular y regular y con los obispos de los votos brasileños, es que en 1955 de las 3.309 parroquias, 2.240 eran atendidas por sacerdotes seculares y las restantes 1.069 por religiosos. ${ }^{38}$ El auge del laicado, en el marco de la Acción Católica especializada con la asesoría de Dom Helder Câmara, es el otro elemento destacado que explica las muchas referencias al diaconado (laical) en los votos.

De los 116 votos enviados desde Brasil a la Comisión Antepreparatoria, casi cuarenta votos contienen una o más referencias a la vida religiosa, que se presentan en sus rasgos más significativos. Los temas principales de las propuestas son la vida del clero y, por su escasez, la restauración del diaconado -con una veintena de menciones, aunque solo algunas dicen relación expresa con vida religiosa-. Sin duda, el voto más original pertenece a Iacobus Coelho (obispo de Maringá), por cuanto propone la institución de "diáconos y diaconisas" (ADAP I-II, VII, 214). ${ }^{39}$ Se puede observar, en una gran cantidad de votos, la referencia a las religiosas y religiosas superioras, lo cual parece un indicativo de una nueva conciencia eclesial en la Iglesia de Brasil. En este sentido, cabe recordar el caso de monseñor Eugenio Sales, uno de los contados obispos latinoamericanos que -ya en 1953- llamó a religiosas para hacerse cargo de parroquias según fuentes históricas. También se puede mencionar el voto de Bezerra Coutinho, al proponer «una mayor participación

37 Beozzo, «Vida cristiana y sociedad en Brasil», 58.

38 Beozzo, «Vida cristiana y sociedad en Brasil», 68.

39 Solo dos votos en todo el mundo plantean el tema de las diaconisas: Coelho de Maringá, Brasil y Uriarte Bengoa de San Ramón, Perú (ADAP I-II, VII 531). Cf. Polanco, «La Iglesia continental que llegaba al Concilio», 725 . 
de religiosas mujeres que pertenecen a la vida activa en tareas apostólicas y parroquiales» (ADAP I-II, VII, 342).

Una mirada al conjunto de votos sobre vida religiosa permite agruparlos en dos: primero, se pueden distinguir los que tratan sobre esta forma de vida en la Iglesia $y$, segundo, aquellos referidos a su realidad propia y específica. En el primer grupo, se destaca ante todo la preocupación por las relaciones entre obispos y religiosos, clero secular y clero regular y religiosos entre sí, con unos quince votos; parece muy indicador que el tema de la exención se ubique en este contexto, lo que da al planteo una forma algo atenuada. ${ }^{40}$ En efecto, se puede señalar que en varios votos se encuentra una consideración positiva en términos de relaciones mutuas: Araújo Sales habla de "nuevas relaciones entre el episcopado y las órdenes o congregaciones religiosas"; otros como Pires, Silveira de Mello y Bueno Couto proponen "cooperación" o "colaboración" entre sacerdotes y religiosos. ${ }^{41}$ Una visión más crítica aparece en otras propuestas que remarcan una subordinación en términos de mayor "dependencia" al obispo diocesano como Da Silva o Berenguer Prado (ADAP I-II, VII, 255, 270). En este marco, se ubican los nueve vota que tratan -de forma breve o extensa- sobre el privilegio de la exención y su "necesaria restricción" (ADAP I-II, VII, 244). ${ }^{42}$ Un caso algo extremo parece ser el voto presentado por monseñor Zorzi, con una formulación que no deja margen de duda: nihil sine Episcopo (ADAP I-II, VII, 163). Completan este grupo los que tratan la cuestión de los religiosos a cargo de parroquias como Pires, Saboia Bandeira de Mello, Reis/Sartori, Wichrowski.

En cuanto a la vida religiosa en sí misma, aparece una diversidad de temas. Por una parte, se encuentran diversas referencias al tema de la "adaptación", en la mayoría de los casos vinculada al há-

40 Un ejemplo interesante de esta acentuación puesta en las relaciones se da en el voto de Brandão Vilela, quien se refiere a normas para las relaciones entre religiosos con la diócesis. Cf. ADAP I-II, VII, 262.

41 Cf. ADAP I-II, VII, 336, 132, 275, 318.

42 Además de la referencia citada en texto de Reis/Sartori, otro voto que destaca la restricción de la exención es el de Mota e Albuquerque. Cf. ADAP I-II, VII, 267. 
bito o vestimenta como se observa en seis votos; ${ }^{43}$ un tema -el de la vestimenta- también presente en relación con los obispos y los sacerdotes en estos años. La renovación de la vida consagrada se expresa, además, por medio de una mención de Brandão Vilela a los institutos seculares (ADAP I-II, VII, 262). Un tema muy importante se manifiesta en el voto de Oliveira y es la institución de «un nuevo sistema de dote para la vida religiosa» (ADAP I-II, VII, 322), porque indica la conciencia de una necesidad de cambio en lo relativo a la estratificación social al interior de las comunidades religiosas. Por último, resulta interesante que una serie de cuatro votos plantee la autorización a superioras y superiores religiosos para dar la comunión en territorios de misión con falta de sacerdotes, lo cual implica un reconocimiento y una valoración de la tarea misionera a la vez que pone en evidencia la escasez de clero en las iglesias locales de Brasil. ${ }^{44}$

\subsection{Colombia}

En condiciones históricas conflictivas, de violencia, el interés fundamental de los obispos -en tiempos de preparación del Concilio- parece ser la preservación de las estructuras intraeclesiales y las preocupaciones se centran en el ámbito de las reformas del derecho, aunque el impacto conciliar los llevará más allá y los acercará a otra forma de vida, más cercana a los pobres. ${ }^{45} \mathrm{El}$ influjo que ha ejercido la vida religiosa a lo largo de la historia de este país, sobre todo en territorios de misión, explica dos cosas: primero, que los obispos busquen una mayor participación de los religiosos en la tarea pastoral de sus diócesis y por lo mismo, segundo, que insistan en el tema de la exención para restringir los privilegios de los religiosos y ejercer un mayor control sobre ellos y su misión.

43 Así, por ejemplo, en los votos de Zorzi, Conventus Episcopalis/Nigri, Brandão Vilela, Aparicio y Wichrowski.

44 Advierten esta situación Fernandes, Ryan, Ferreira de Macedo y Wichrowski. Cf. ADAP I-II, VII, 209.302.315.328.

45 Cf. Ignacio Madera Vargas SDS, «Colombia y Venezuela», en José Oscar Beozzo (ed.), Cristianismo e iglesias de América Latina en visperas del Vaticano II (San José: Editorial Dei, 1992), 165-178, 168ss. 
De 54 obispos consultados en Colombia, se prepararon 35 respuestas para enviar a Roma, de las cuales 3 fueron firmadas por dos obispos. En ellas, se evidencia cierta uniformidad con respecto a la doctrina y a cuestiones relacionadas con la vida religiosa y la exención. Las peticiones de algunos prelados misioneros presentan «observaciones críticas muy sugerentes con respecto al resto del episcopado y con la práctica misionera de los religiosos y su formación para la misión». ${ }^{46}$ Entre los votos de tipo doctrinal, se destacan nueve peticiones a favor de la definición de la mediación de María, cuatro que solicitan definir la doctrina del "cuerpo místico" y cuatro que condenan el comunismo. Entre las propuestas relativas a la disciplina del clero y del pueblo cristiano, el tema más recurrente es la revisión de la exención -con mención en unos 15 votos- motivada por la suplencia ante la falta de clero y la participación en la vida pastoral de las diócesis. Trece peticiones buscan simplificar el Oficio Divino; otras se refieren a la comunión en Pascua o a la celebración de la misa, nueve al diaconado permanente y cinco a la nulidad matrimonial. En términos generales, según I. Madera Vargas, «se busca más bien fortalecer el régimen jerárquico con declaraciones doctrinales que clarifiquen el sentido teológico de ese mismo régimen»;47 la cuestión social queda más bien inadvertida, como se puede observar también en otros países.

Entre las propuestas que mencionan la vida religiosa, se destacan ocho, de las cuales varias son breves y cuatro sobresalen por su extensión, sus estructuras en el orden de contenidos y el detalle canónico. ${ }^{48}$ Respecto a los temas en relación con la vida religiosa, además de la exención y las relaciones de los religiosos con el clero secular, se presenta una gran variedad. La temática más repetida en distintos votos trata sobre cuestiones económicas relativas a los

46 Madera Vargas SDS, «Colombia y Venezuela», 166.

47 Madera Vargas SDS, «Colombia y Venezuela», 173.

48 Los ocho votos pertenecen a Jaramillo Tobón (Jericó), cuya fecha no figura en las actas; Roig y Villalba (vicario apostólico en Valledupar); Trujillo Arango (vicario capitular en Manizales); Botero Salazar (arzobispo de Medellín); Jauregui (Zipaquira), entregadas con prontitud; también se cuentan tres respuestas tardías: Duque Villalba (arzobispo de Manizales); Alvarez Restrepo (Pereira) y Rivera Mejía (Socorro y San Gil). 
institutos o sus miembros -como cargas, provisión, remuneraciones y limosnas- ${ }^{49}$ Un voto ilustrativo, en el conjunto, puede ser el de monseñor B. Alvarez Restrepo: «Sobre la adhesión de las comunidades de religiosos a los obispos: No descuiden demasiado a algunas comunidades religiosas exentas de la autoridad episcopal, las cuales trabajan poco en la acción social y católica. Ojalá el Concilio decida alguna de estas cosas» (ADAP I-II, VII, 429). Otros aportes se centran en la cuestión de los votos y la profesion (Roig y Villalba), los institutos seculares (Botero Salazar), la necesidad de determinar los objetivos de cada instituto y la federación de institutos. Sobre la adaptación de la vida religiosa a las exigencias del mundo contemporáneo se menciona la simplificación del oficio para las religiosas, el hábito, la clausura (Jaramillo Tobón; Botero Salazar; Trujillo Arango). También se hace referencia a la necesidad de colaboración de los religiosos en la tarea pastoral de la diócesis.

\subsection{México}

La jerarquía mexicana de la Iglesia católica se puede identificar como predominantemente pietista, muy preocupada por la ortodoxia doctrinal, muy fiel y devota de la autoridad papal y exigente en la disciplina y la sumisión de sus subordinados como muestra de fidelidad. ${ }^{50}$ De los 52 obispos consultados en México, se enviaron a la comisión 36 propuestas individuales y una propuesta colectiva de la Conferencia Episcopal, que reunió a 12 obispos. En su análisis a los contenidos temáticos, Jesús García registra que 37 de las respuestas suscribieron la solicitud de definición del dogma de la maternidad espiritual de María y menciona que, segundo en orden de importancia, se ubica el tema de las relaciones entre los obispos y el clero regular, con nueve votos. Esta temática se explica por la

49 El tema de la limosna aparece en cuatro votos y en dos de ellos (Alvarez Restrepo y Trujillo Arango) se alude a una situación conflictiva con respecto de las limosnas y las órdenes mendicantes.

50 Cf. Jesús García, "México», en José Oscar Beozzo (ed.), Cristianismo e iglesias de América Latina en vísperas del Vaticano II (San José: Editorial Dei, 1992), 199-204, 204. 
composición religiosa de dos tercios del clero de la Arquidiócesis de México, mientras que en el resto del país la presencia de los religiosos sólo alcanzaba el 30\% del clero y el 70\% estaba representado por clero diocesano. Siendo México uno de los países con mayor proporción de clero en América Latina, se comprenden las tensiones entre los obispos y los religiosos. ${ }^{51}$ Según la visión de J. García, algunas temáticas más creativas, vinculadas a la dimensión ad extra de la Iglesia fueron: el ecumenismo y la cuestión social y política, sobre todo los obreros y los riesgos del comunismo; sólo esporádicamente algunos obispos en medios indígenas hicieron referencia al tema de la pobreza de la Iglesia de una manera profética y visionaria, al plantear una crítica al clero y a las instituciones religiosas. También sobre la población indígena, 15 millones por entonces, hubo algunas voces que pidieron una adaptación cultural, litúrgica y lingüística, dando lugar a planteos posteriores en relación con la defensa de los derechos humanos.

Los votos de obispos mexicanos que se refieren al tema de la vida religiosa son diecinueve. ${ }^{52}$ Algunos de ellos son muy breves y otros extensos, destacándose por su estructura de temática múltiple, en extremo detallados y, sobre todo, atentos a las cuestiones canónicas. Con respecto a los temas considerados, diez de estos votos tratan sobre la exención de los religiosos, considerándola más bien un privilegio y reclamando una exposición más clara del concepto (Fortini Gomez). También se refieren a la colaboración entre el clero regular y secular (Del Campo Padilla; Fortini Gomez), la cual demanda en su situación concreta una unidad en el trabajo apostólico, sobre todo en las diócesis carentes de suficiente clero diocesano. El

51 Cf. García, «México», 202.

52 Miranda y Gómez (arzobispo de México) junto a Orozco Lomelin, uno de sus auxiliares, sin fecha en las actas; Alba Palacios (auxiliar de México), Villareal y Fierro (Tehuantepec), Del Campo Padilla (León), Yerena y Camarena (Huejutla), López Avina (Zacatecas), Corripio Ahumada (Tampico), Márquez Toriz (arzobispo de Puebla), Hernández Urtado (Tapachula), Garibi y Rivera (arzobispo de Guadalajara), Ruiz y Solórzano (arzobispo emérito de Yucatán), Abascal Salmerón (auxiliar de Puebla), Espino y Silva (arzobis po de Monterrey), De Alba y Hernández (Colima), Sánchez Tinoco (Papantla), Raimondi (delegado apostólico en México), Fortini Gómez (arzobispo de Antequera) de respuesta rápida y Talamas Camandari (Ciudad Juárez), Aguirre García (Culiacán), entregado tardíamente. 
voto de monseñor L. Aguirre García formuló aspectos principales: «Mientras el Concilio persigue la unidad de la Iglesia, conviene máximamente que se atienda ante todo a la unión entre ambos cleros. Deben, por tanto, también los religiosos exentos, sujetarse a la jurisdicción del obispo donde se encuentre la casa religiosa» (ADAP I-II, VI, 180). El argumento de la unidad de la Iglesia en este contexto es, sin duda, importante y también está presente en otros vota significativos del contexto europeo. ${ }^{53}$ Además de lo mencionado, los obispos mexicanos realizaron propuestas sobre los institutos seculares (Aguirre García, Garibi y Rivera), algunas cuestiones relativas a la disciplina interna de los institutos y al sostenimiento económico de los mismos, así como acerca de la adaptación de la vida religiosa.

En conjunto, se pueden destacar dos aspectos entre otros: un episcopado en una relación algo tensa con el clero religioso -tal vez sobre todo en la arquidiócesis de México- y las semillas de un compromiso con los pobres, vinculadas a la realidad de una presencia multitudinaria de indígenas.

\section{Algunas reflexiones finales}

Una lectura de los votos de los obispos de Argentina, Brasil, Colombia y México, enviados en respuesta a la consulta encargada por Juan XXIII en 1959, permite observar algunos núcleos de preocupación e interés y también una panorámica general de los temas ausentes, por ejemplo, en relación con algunas dimensiones específicas de la vida religiosa y su renovación. Desde una mirada comparativa, de tipo cuantitativa, se puede observar que la presencia de las religiosas y religiosos en la Iglesia de los países analizados es destacada, pero se refleja diferenciadamente en los votos de los obispos: en Argentina y México, el tema aparece prácticamente en la mitad de las propuestas, con énfasis en la exención y la unión del clero; mientras que, en Brasil y Colombia, solo emerge en alrededor

53 Cf. Schmiedl, Das Konzil und die Orden, 178. 
de un tercio de los aportes. En todos los casos, la relación de la vida religiosa con los obispos y el clero se presenta como central, mientras que las referencias a las mutuas relaciones entre las diversas formas de vida en la Iglesia son menos frecuentes, con excepciones como la de Enrique Rau, quien urge en toda la Iglesia a una más estricta "coordinación" de los fieles y de las asociaciones religiosas y laicales con y hacia el obispo (cf. ADAP I-II, VII, 62). También se constatan algunas referencias, esporádicas, a la Iglesia como cuerpo de Cristo, que remiten a la eclesiología jurídica y societaria de Mystici Corporis Christi, dada por Pío XII en 1943 y vigente sin duda en los años previos al Concilio. La consideración de temas propios de la vida religiosa no se destaca en particular o aparece de manera secundaria o indirecta al tratarse sobre otras temáticas, como sucede con la mención tangencial de la segregación social en las congregaciones religiosas, aludida en el contexto de otorgar facultades restringidas a superiores religiosos de ambos sexos para distribuir la comunión (cf. ADAP I-II, VII, 315-316).

La escasez de clero es, sin duda, un denominador común que capta la atención del episcopado latinoamericano y centroamericano, según puede verse expresamente en la Conferencia de Río de Janeiro y su llamado a religiosos y religiosas a colaborar con las necesidades apostólicas de diócesis y parroquias, así como en un gran número de votos sobre diversos temas. Esta preocupante realidad pastoral parece condicionar a los obispos y en cierto modo dificultar una comprensión más integral de la vida religiosa a causa de la urgencia apostólica de la Iglesia. Al mismo tiempo, la problemática de la falta de clero refleja claramente la situación de las iglesias locales, algo replegadas sobre sí mismas, atentas a su realidad numérica y a su vitalidad ad intra. Indudablemente las necesidades apostólicas de los grandes territorios eclesiásticos producen una mirada algo limitada de la vida religiosa y reducen la posibilidad de comprensión sobre sus propias búsquedas y dificultades. En este contexto, la vida religiosa es considerada, de forma casi imperceptible e inevitable, como una fuente de personal idóneo para hacer frente a las demandas apostólicas de la vida diocesana, de allí la prioridad puesta 
sobre la autoridad del obispo y la sujeción de los religiosos/as a sus requerimientos para responder a los desafíos de sus extensas diócesis, quedando opacada la consideración del aporte específico que religiosas y religiosos están llamados a ofrecer en la Iglesia. ${ }^{54}$

De forma coincidente con lo anterior, la visión eclesiológica preconciliar, de orientación clericalista y juridicista, representa sin lugar a dudas un sesgo que interviene en la lectura episcopal sobre la vida religiosa en general, si bien se pueden observar una gran variedad de posiciones y matices en los diversos votos. ${ }^{55}$ La legítima preocupación de los obispos por el clero genera una mirada algo funcional acerca de la vida religiosa, corriéndose el riesgo de ser considerada solo en función de su colaboración con el obispo diocesano y el clero secular. El énfasis puesto en el tema del privilegio de la exención en algunos casos y en las relaciones entre el obispo y los religiosos / as en otros, pone de manifiesto el elemento jerárquico de la perspectiva. Los votos oscilan entre visiones más negativas que ven la exención como un daño grave a la autoridad del ordinario $^{56}$ y otras, más positivas, que sin mencionar la exención intentan instalar una nueva comprensión de las mutuas relaciones entre los obispos y los religiosos o el clero secular y el clero regular (Brandão Vilela, Araújo Sales, Bezerra Coutinho). También, en esta línea, se han de entender las preocupaciones relativas a la unidad eclesial o a la cooperación entre el clero secular y regular, si bien estas referencias de conjunto a la Iglesia -asociadas en general al concepto de cuerpo místico- son mucho menos frecuentes. Estas relaciones se plantean muchas veces en términos negativos de "restricción" de privilegios y "dependencia al obispo" como aparece de manera

54 Sobre esta situación se advertía años más tarde desde otro contexto, cf. Jean-Marie Tillard, «El misterio de la comunidad», CuadMon 19 (1971): 129-154.

55 Cf. Rodrigo Polanco, «Cambios en la conciencia eclesial en América Latina, previo a la conferencia de Medellín (1968). Estudio a partir de la literatura clasificada en la Base de Datos "Seladoc" ", CrSt 41 (2020): 171-224, 193ss.

56 Como ejemplo se puede citar la posición de M. Miranda y F. Orozco, arzobispo y obispo auxiliar de México (ADAP I-II, VI, 223) citada por Polanco, «La Iglesia continental que Ilegaba al Concilio», 717; caben recordar las tensiones particulares entre obispos y religiosos en la arquidiócesis de esta ciudad. 
ejemplar en la citada expresión nihil sine Episcopo (APAP I-II, VII, 163), pero otras veces también se presentan desde un punto de vista diferente, acentuando la idea de "colaboración" para edificar el cuerpo místico (I-II, VII, 318). Las dificultades entre el episcopado y la vida religiosa se manifiestan de diversos modos, pero sobresalen algunos aspectos particulares que llegan a expresarse, incluso, en la forma de críticas y que merecen una mención: las parroquias a cargo de los religiosos (Rau, Mozzoni), la falta de disponibilidad de algunas comunidades de religiosas/os para ir a sectores marcados por la pobreza (Fasolino, Schell, Hernández Hurtado) y diversos asuntos económicos, junto a otros.

Con respecto a los asuntos propios de la vida religiosa, son importantes los indicadores de la renovación de las órdenes y congregaciones religiosas, asociados casi siempre a la cuestión del hábito o la vestimenta, lo cual denota un tipo de lectura algo externa, que no se vincula necesariamente, de forma directa o expresa, a las dimensiones internas o carismáticas de esta forma de vida. La palabra "adaptación" se hace presente en diversos votos (Aramburu, Zorzi, Coehlo, Brandão Vilela, Aguirre García, Trujillo Arango); ella también se menciona con palabras semejantes como "reforma" (Iriarte) o "aggiornamento" (Zorzi). Estos vocablos aparecen por lo general de un modo genérico, sin una explicitación de lo que se quiere alentar o validar en la vida religiosa, pero algunas veces son vinculados a nuevas perspectivas con alguna explicación, como en el voto del cardenal J. Garibi y Rivera, arzobispo de Guadalajara, quien propone una adaptación de preceptos y costumbres de la disciplina eclesiástica sin perjuicio del compromiso con la vida cristiana, en referencia a las vestimentas obsoletas que dificultan el ejercicio apostólico o la apertura de las religiosas/os de vida contemplativa a ciertas formas apostólicas (cf. ADAP I-II, VI, 198-199). La comprensión de la vida religiosa en relación con el estado de perfección $\mathrm{u}$ otros elementos relacionados con su identidad y misión están prácticamente ausentes en los vota, con excepción de propuestas de algunos obispos religiosos o con mayor conocimiento de la situación de esta forma de vida y sus exigencias de renovación 
(Kemerer, Botero Salazar, Garibi y Rivera). El dinamismo de la vida consagrada en la comunidad eclesial se expresa, además, en algunos temas de mención menos frecuente como los institutos seculares, las nuevas fundaciones y las órdenes terceras.

El aggiomamento que comienza a darse en la vida religiosa se hace visible, finalmente, a través de temáticas transversales que van apareciendo en el conjunto de las propuestas. Uno de ellos, sin duda relevante, es el que se refiere a la realidad de las religiosas mujeres, que recibe variadas menciones en los vota de los obispos. Si bien no son propuestas que afirman de manera directa y explícita la importancia de la vida religiosa femenina en América Latina y Central, sí manifiestan diversos aspectos emergentes que hablan de una nueva conciencia eclesial, en la cual las religiosas son un sujeto valioso e insoslayable. En este sentido, se presentan propuestas relacionadas con el servicio pastoral como las alusiones referidas a una mayor participación en las tareas apostólicas y parroquiales (Bezerra Coutinho), la formación de las religiosas y su aptitud para la enseñanza de la religión (Raspanti) e, incluso, la institución de diaconisas (Coehlo). Otros votos hacen referencia a la ampliación de facultades a superioras y superiores religiosos para distribuir la comunión ante la falta de clero; también se alude al permiso dado a las hermanas, en el templo o capilla, para tomar la Eucaristía con la propia mano (Mota e Albuquerque). Estas aperturas manifiestan la voluntad de otorgar mayor autonomía a la vida religiosa femenina y son expresiones del cambio profundo que se estaba gestando en los años del preconcilio. Entre los aspectos críticos que algunos obispos ponen de manifiesto, cabe destacar el voto de Bampi, en el contexto de la vivencia de la pobreza evangélica, al señalar que las hermanas a menudo no son tratadas como hijas sino como esclavas, en aparente referencia a los abusos derivados de la segregación social en las congregaciones religiosas femeninas (cf. ADAP I-II, VII, 339). Estos son algunos ejemplos que evidencian la particular atención pastoral dada por los obispos a la adaptación de la vida religiosa femenina, cuya vitalidad y aporte específico se hará más visible en los años siguientes al Concilio. 
En fin, los vota de los obispos latinoamericanos y centroamericanos sobre la vida religiosa ¿son un retrato de una forma de vida o de la eclesiología preconciliar? Posiblemente, se trata de una mirada a las religiosas y religiosos desde la perspectiva de una parte del episcopado continental en los tiempos que precedieron a la celebración del Concilio Vaticano II, un retrato de un capítulo de la eclesiología previa al concilio ecuménico que estaba por iniciarse a la vez que un retrato limitado de una forma de vida. Los votos de Argentina, Brasil, Colombia y México que tratan sobre la vida religiosa ilustran una diversidad de elementos característicos de la Iglesia que precedió al Vaticano II en América Latina, ciertas tensiones y búsquedas de unidad entre obispos y religiosos, además de un conjunto de aspectos que hablan de las religiosas y los religiosos en el camino hacia la renovación.

\section{Bibliografía}

Azcuy, Virginia Raquel. «La inserción como fruto del aggiomamento conciliar», en Ana Lourdes Suárez; Brenda Carranza; Mariana Facciola; Lorena Fernández Fastuca (eds.), Religiosas en América latina: memorias y contextos. Buenos Aires: Instituto de Investigaciones Facultad de Ciencias Sociales UCA - CONICET, 2020, 329-335.

Beozzo, José Oscar (ed.). Cristianismo e iglesias de América Latina en vísperas del Vaticano II. San José: Editorial Dei, 1992.

Beozzo, José Oscar. «Vida cristiana y sociedad en Brasil», en José Oscar Beozzo, (ed.), Cristianismo e iglesias de América Latina en vísperas del Vaticano II. San José: Editorial Dei, 1992, 49-81.

Bidegain, Ana María. Participación y protagonismo de las mujeres en la historia del catolicismo latinoamericano. Buenos Aires: San Benito, 2009.

Codina, Víctor. «Hacia una vida religiosa latinoamericana», en Víctor Codina; Noë Zeballos, Vida Religiosa. Historia y Teología. Madrid: Ediciones Paulinas, 1987, 173-194. 
Concilio Vaticano II. Acta et Documenta Concilio Oecumenico Vaticano II Apparando: Consilia et vota episcoporum et praelatorum. Series I: Antepraeparatoria. Vaticanus: Typis Poliglottis Vaticanis, 19601961, Vol II, Pars VI-VII.

Confederación Latinoamericana de Religiosos (CLAR). Vida religiosa femenina en América Latina y el Caribe. Memoria histórica 19591999. Lima: CEP, 2003 (3 volúmenes).

Fouilloux, Étienne. «La fase antepreparatoria (1959-1960). El lento camino para salir de la inercia», en: G. Alberigo (dir.), Historia del Concilio Vaticano II, Volumen I, El catolicismo hacia una nueva era, el anuncio y la preparación (enero 1959-septiembre1962). Salamanca: Ediciones Sígueme, 1999, 63-154.

García, Jesús. «México», en José Oscar Beozzo (ed.), Cristianismo e iglesias de América Latina en vísperas del Vaticano II. San José: Editorial Dei, 1992, 199-204.

García Martín, Julio CMF. Voz «Exención», en A. Aparicio Rodríguez CMF; Joan M. Canals Casas CMF (dir.), Diccionario Teológico de la Vida Consagrada. Madrid: Publicaciones Claretianas, 2009, 640-648. Madera Vargas, Ignacio. SDS, «Colombia y Venezuela», en José Oscar Beozzo (ed.), Cristianismo e iglesias de América Latina en vísperas del Vaticano II. San José: Editorial Dei, 1992, 165-178.

Mallimaci, Fortunato. «Argentina», en José Oscar Beozzo, (ed.), Cristianismo e iglesias de América Latina en vísperas del Vaticano II. San José: Editorial Dei, 1992, 97-120.

Melloni, Antonio. «Per un approccio storico-critico ai Consilia et vota della Fase Antepraeparatoria del Vaticano II». Rivista di storia e letteratura 26,3 (1990): 556-576.

Polanco, Rodrigo. «La Iglesia continental que llegaba al Concilio. Eclesiología de los vota de los obispos latinoamericanos para el Concilio Vaticano II». Perspectiva Teológica 52 (2020): 705731.

Polanco, Rodrigo. «Cambios en la conciencia eclesial en América Latina, previo a la conferencia de Medellín (1968). Estudio a partir de la literatura clasificada en la Base de Datos "Seladoc" ». CrSt 41 (2020): 171-224. 
Quiñones, Ana, STJ. Del "estado de perfección" a "seguir a Jesús con el pueblo pobre". El comienzo de la vida religiosa inserta en medios populares en Argentina (1954-1976). Buenos Aires: Talleres Gráficos de IRO, 1999.

Rivas, Nelda. Ellas fueron a anunciarlo. Parroquias animadas por comunidades religiosas femeninas en Uruguay. Montevideo: OBSUR/ Doble clic editoras, 2008.

Salvia, Ernesto. «La recepción del Concilio Vaticano II en la Argentina». Archioum 30 (2014): 299-310.

Schmiedl, Joachim. Das Konzil und die Orden. Krise und Erneuerung des gottgeweihten Lebens. Vallendar-Schönstatt: Patris Verlag, 1999.

Zeballos, Noë. «Visión histórica de la vida religiosa en América Latina», en Víctor Codina; Noë Zeballos, Vida Religiosa. Historia y Teología. Madrid: Ediciones Paulinas, 1987, 75-108.

Wulf, Friedrich. «Fenomenología teológica de la vida religiosa», en: Johannes Feiner; Magnus Löhrer (dir.), Mysterium Salutis. Manual de Teología como historia de salvación, Volumen IV, tomo II. Madrid: Cristiandad, 1975, 438-472. 